\title{
Extracapsular cataract surgery with lens implantation in diabetics with and without proliferative retinopathy
}

\author{
I A Cunliffe, D W Flanagan, N D L George, R J Aggarwaal, A T Moore
}

\begin{abstract}
In a retrospective study we have examined all diabetics (66 operated eyes) and an equal number of non-diabetic matched controls who underwent extracapsular cataract extracation (ECCE) with intraocular lens (IOL) implantation over a two-year period ending in December 1987. Of the diabetic patients' $76 \%$ eyes improved by at least two lines of Snellen acuity postoperatively. Of these patients $68 \%$ eyes and of the control eyes $83 \%$ achieved an acuity of $6 / 12$ or better. In the diabetics the visual outcome depended on the state of the retinopathy and in particular the maculopathy. The diabetic group had a greater incidence of postoperative inflammation, but the major complications were related to continuing neovascularisation. Early postoperative laser photocoagulation may help to prevent these proliferative complications, and, provided a large, adequate capsulotomy is performed for capsular thickening, the presence of an IOL does not interfere with this photocoagulation. We also advise early postoperative assessment, and treatment if necessary, of any maculopathy. Diabetic retinopathy should no longer be regarded as a contraindication to intraocular lens insertion.
\end{abstract}

Diabetes mellitus is a common condition, affecting $1-2 \%$ of the population. Cataract occurs earlier in diabetics than in non-diabetics, and both cataract and retinopathy are related to the age of the patient and the duration of the diabetes. ${ }^{12}$ Cataract surgery in diabetics may be performed to improve vision or to allow assessment and treatment of retinopathy. The benefits of intraocular lenses (IOLs) over other forms of aphakic correction are well known, and most surgeons now perform extracapsular cataract extraction (ECCE) with IOL implantation for senile cataract. Currently in the United Kingdom over $90 \%$ of cataract extractions include implantation of an IOL. ${ }^{3}$ IOL implantation in diabetics, especially in those with proliferative retinopathy, is still controversial ${ }^{3-7}$ and is still listed by some manufacturers as a contraindication to their use. We now routinely implant lenses in all diabetics, and this study reviews our results.

\section{Patients and methods}

We have reviewed 66 consecutive diabetic patients (72 operated eyes) undergoing ECCE plus IOL under the care of two consultant ophthalmologists over a two-year period ending in December 1987. The minimum follow-up was 18 months. Six patients were excluded from the study: four who died within 18 months of surgery, one myopic patient (no IOL), and one patient lost to follow-up. Six patients have had both eyes operated on. Sixty-six eyes were included in the study, of which 63 have been reexamined by one of the authors. Each diabetic eye was matched for age and surgeon with a nondiabetic eye undergoing ECCE $+\mathrm{IOL}$; this formed the control group, who were also recalled for examination. Three of the diabetics and two of the controls who have died, but who had completed more than 18 months' follow-up, are included.

All patients received preoperative mydriatic drops, and patients under the care of one of the consultants received preoperative indomethacin $(0.5 \%)$ drops to help prevent surgically induced miosis. The surgical procedure was a standard corneal section ECCE with posterior chamber two-piece J-loop IOL, with the following exceptions: two eyes in each group had limbal sections; one eye in each group had an anterior chamber IOL; two eyes of diabetic patients had one-piece (all polymethyl methacrylate) IOLs.

There was no statistically significant difference between the control group and the diabetic group when compared for age $(t$ test $p>0 \cdot 1)$, sex, anaesthetic, or use of sodium hyaluronate (Healon id) or indomethacin $\left(\chi^{2}, p>0.5\right)$. There were 28 males and 38 females in each group, and their ages ranged from 22 to 91 years (mean 70.5 ) in the diabetic group and from 46 to 88 years (mean 73.9) in the control group. The mean follow-up time was 2.61 years. In each group 44 eyes $(66.7 \%)$ were operated on by one of two consultants, and 22 eyes $(33 \cdot 3 \%)$ by one of seven junior staff.

In the diabetic group 11 patients $(16 \cdot 7 \%)$ were controlled by diet, $39(59 \cdot 1 \%)$ were controlled on oral hypoglycaemic agents alone, $15(22 \cdot 7 \%)$ were on insulin, and one $(1 \cdot 5 \%)$ required both

\begin{tabular}{lll}
$\begin{array}{l}\text { Table } 1 \\
\text { groups }\end{array}$ & Coexistent diseases in the diabetic and control \\
\hline Coexistent disease & Diabetics & Controls \\
\hline ARMD & 5 & 2 \\
COAG & 5 & 6 \\
Endothelial guttata & 2 & 3 \\
Branch vein occlusion & 1 & 1 \\
Iritis & 0 & 1 \\
Amblyopia & 1 & 0 \\
Lamellar hole & 0 & 1 \\
Interstitial keratitis & 1 & 0 \\
Amiodarone keratopathy & 0 & 1 \\
Ocular hypertension & 0 & 1 \\
Pituitary adenoma & 0 & 1 \\
\hline
\end{tabular}

ARMD = age related macular degeneration. $\mathrm{COAG}=$ chronic open angle glaucoma. 
Table 2 Final visual outcome

\begin{tabular}{|c|c|c|c|c|c|}
\hline & \multicolumn{5}{|c|}{ Final visual acuity: number of eyes (\%) } \\
\hline & $\geqslant 6 / 12$ & $6 / 18-6 / 24$ & $6 / 36-6 / 60$ & $<6 / 60$ & Total \\
\hline $\begin{array}{l}\text { Controls } \\
\text { Diabetics } \\
\text { No retinopathy } \\
\text { Background }\end{array}$ & $\begin{array}{l}55(83 \cdot 3) \\
45(68 \cdot 1) \\
28(84 \cdot 8)\end{array}$ & $\begin{array}{l}7(10 \cdot 6) \\
6(9 \cdot 1) \\
4(12 \cdot 1)\end{array}$ & $\begin{array}{l}3(4 \cdot 5) \\
7(10 \cdot 1) \\
0(0)\end{array}$ & $\begin{array}{l}1(1 \cdot 5) \\
8(12 \cdot 2) \\
1(3 \cdot 0)\end{array}$ & $\begin{array}{l}66 \\
66 \\
33\end{array}$ \\
\hline $\begin{array}{l}\text { + Maculopathy } \\
\text { - Maculopathy }\end{array}$ & $\stackrel{3}{10}(56 \cdot 5)$ & $\begin{array}{l}0 \\
1(4 \cdot 3)\end{array}$ & $\begin{array}{l}4 \\
1(21 \cdot 7)\end{array}$ & $\begin{array}{l}4 \\
0(17 \cdot 4)\end{array}$ & 23 \\
\hline $\begin{array}{l}\text { Proliferative } \\
\text { + Maculopathy } \\
\text { - Maculopathy }\end{array}$ & $\begin{array}{l}2 \\
2(40)\end{array}$ & $\begin{array}{l}1 \\
0(10)\end{array}$ & $\begin{array}{l}2 \\
0(20)\end{array}$ & $\begin{array}{l}3 \\
0(30)\end{array}$ & 10 \\
\hline
\end{tabular}

$+=$ With. $-=$ Without.

Table 3 Diagnosis in eyes failing to achieve postoperative acuity of $6 / 12$ or better

\begin{tabular}{lllll}
\hline & & \multicolumn{2}{l}{ Diabetic retinopathy } \\
\cline { 3 - 5 } & Controls & $N i l$ & Background & Proliferative \\
\hline ARMD & 7 & 2 & 0 & 0 \\
Diabetic maculopathy & 0 & 1 & 9 & 6 \\
Macular vein occlusion & 1 & 0 & 0 & 0 \\
Myopic maculopathy & 1 & 0 & 0 & 0 \\
Retinal detachment & 1 & 0 & 0 & 0 \\
Corneal oedema & 0 & 0 & 1 & 0 \\
Amblyopia & 0 & 1 & 0 & 0 \\
Endophthalmitis & 0 & 1 & 0 & 0 \\
Lamellar hole & 1 & 0 & 0 & 0 \\
\hline
\end{tabular}

ARMD=age related macular degeneration

insulin and oral medication. The duration of diabetes in the oral hypoglycaemic group ranged from 1 to 42 years (mean 12.3) and in the insulin dependent group from 2 to 49 years (mean 22.4). Thirty-three patients $(50 \%)$ had no retinopathy, $23(34 \cdot 8 \%)$ had background retinopathy (11 with maculopathy), and $10(15 \cdot 2 \%)$ had proliferative retinopathy (8 with maculopathy). Several coexistent diseases were present preoperatively (Table 1).

\section{Results}

\section{VISUAL RESULTS}

There was no statistically significant difference in visual outcome (defined as $\geqslant 6 / 12$ vision) between controls and diabetics without retinopathy $\left(\chi^{2}, p>0.5\right)$. Diabetics with retinopathy had a significantly poorer outcome when compared with controls $\left(\chi^{2}, \mathrm{p}<0.01\right)$. The visual results were poorest in those with diabetic

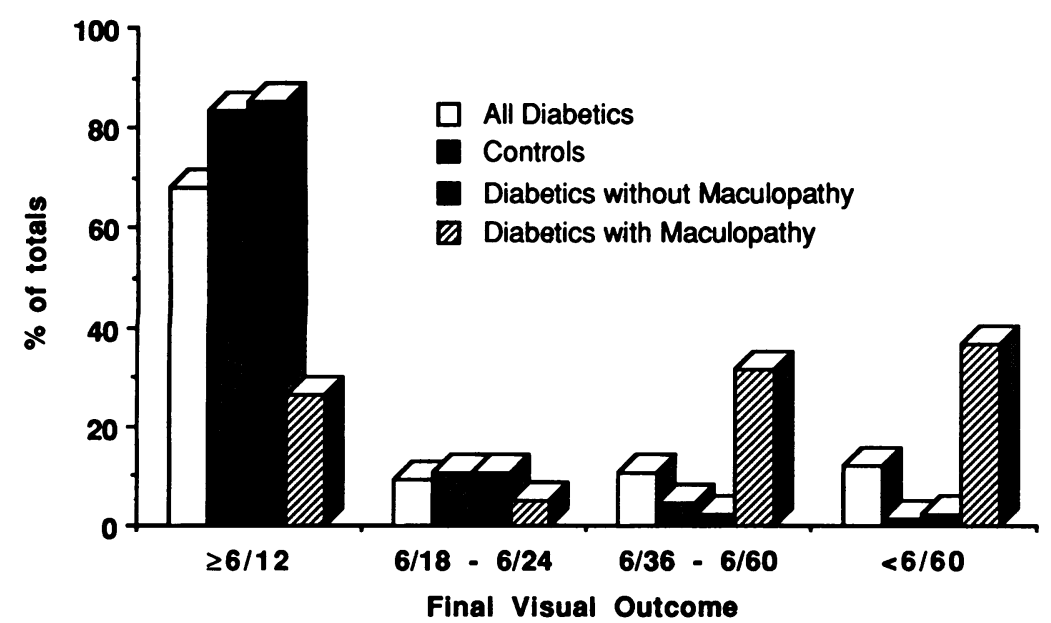

Figure 1 Histogram showing the final visual outcome of diabetic eyes with and without maculopathy and controls. maculopathy or proliferative retinopathy (Table 2, Figs 1, 2). The main causes for an acuity of $<6 / 12$ were age related macular degeneration and diabetic maculopathy (Table 3 ).

In eyes with proliferative retinopathy or maculopathy it may be more useful to consider improvement in vision rather than final visual acuity. In the proliferative group six of 10 eyes showed an improvement of $\geqslant 2$ lines Snellen acuity, and in those with maculopathy seven of 19 showed an improvement of $\geqslant 2$ lines Snellen acuity (Fig 3).

PROGRESSION OF RETINOPATHY

Twenty-five diabetics showed progression of retinopathy in the follow-up period. Five eyes without retinopathy preoperatively developed background retinopathy (one with maculopathy). In the background group two eyes developed a new maculopathy, four eyes showed progression of pre-existing maculopathy, and six eyes developed preproliferative or proliferative retinopathy. In these last six eyes the maculopathy also progressed (in four within six months of surgery), while the fellow eye remained stable. In the proliferative group five eyes developed further new vessels and six showed progression of their maculopathy (three within six months of surgery). Overall, nine eyes developed severe maculopathy in the early postoperative period. Seven of these had pre-existing maculopathy and five had had previous laser photocoagulation.

Seventeen eyes required laser treatment postoperatively. Three eyes had panretinal photocoagulation (PRP) only, seven eyes had focal macular treatment only, and seven eyes had combined PRP and focal macular treatment. In none of these cases did the presence of an IOL prevent adequate photocoagulation.

\section{COMPLICATIONS}

There were few operative complications. In the control group, there was one case of vitreous loss and one posterior capsule tear. There were no operative complications in the diabetic group.

Of the postoperative complications macular oedema (diabetic and cystoid), severe inflammation, rubeosis iridis, neovascular glaucoma, and vitreous haemorrhage occurred more frequently in the diabetic group (Table 4). Four diabetics' eyes and five control eyes developed classical cystoid macular oedema postoperatively; all

Table 4 Postoperative complications

\begin{tabular}{lcc}
\hline Postoperative complications & Diabetics & Controls \\
\hline Rubeosis and neovascular glaucoma & 4 & 0 \\
Macular oedema (diabetic and cystoid) & 17 & 5 \\
Severe inflammation & 4 & 2 \\
$\quad$ Iritis & 1 & 1 \\
Sterile hypopyon & 1 & 0 \\
Fungal keratitis & 1 & 0 \\
Endophthalmitis & 1 & 0 \\
Suture infiltrate & 4 & 0 \\
Vitreous haeinorrhage & 9 & 6 \\
Synechiae to IOL & 23 & 17 \\
Capsular thickening & 2 & 0 \\
IOL malposition & 1 & 2 \\
Iris prolapse & 0 & 1 \\
Retinal detachment & 1 & 0 \\
Corneal decompensation & &
\end{tabular}




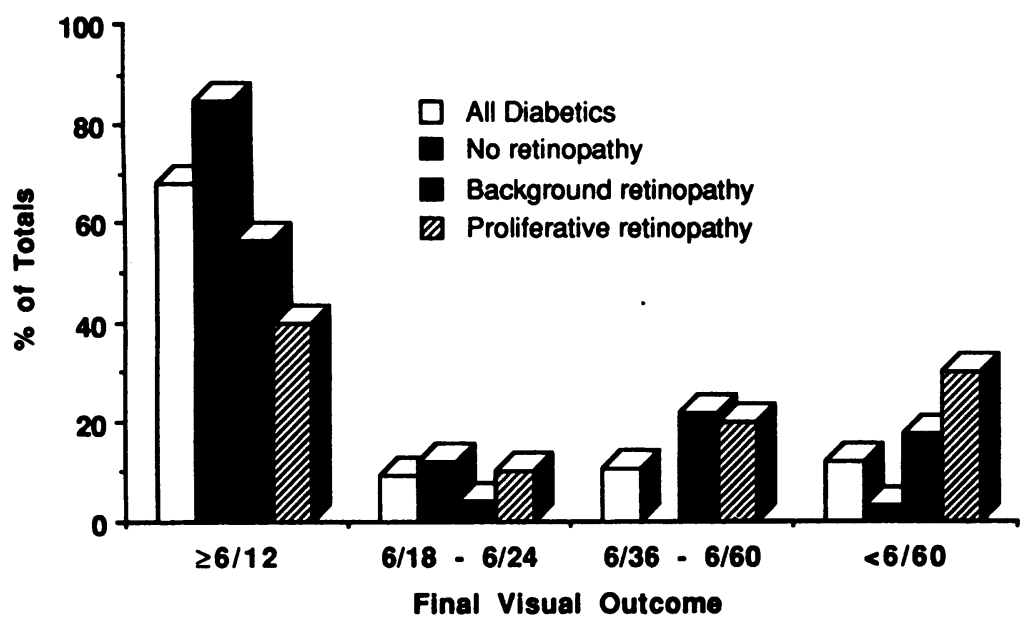

Figure 2 Histogram of the final visual outcome of diabetic eyes with and without retinopathy.

resolved completely. Thirteen diabetics developed diabetic macular oedema in the follow-up period. Seven diabetics' eyes showed evidence of continuing neovascularisation; three developed vitreous haemorrhage and four developed rubeosis iridis. Three of the latter group progressed to neovascular glaucoma. In addition one diabetic patient's eye had a vitreous haemorrhage due to posterior vitreous detachment. The three eyes that developed neovascular glaucoma achieved a final vision of $<6 / 60$. In the fourth case the rubeosis regressed after PRP with the retention of $6 / 12$ vision and a normal intraocular pressure.

Severe inflammation or infection, defined as iritis persisting for more than six weeks postoperatively, endophthalmitis, or keratitis, was more common in the diabetic group (Table 4).

\section{Discussion}

In the past diabetic retinopathy has been considered a contraindication to IOL implantation, though many surgeons now routinely implant IOLs in diabetics. Although there have been several reports of the results of cataract extraction with implants in diabetics, ${ }^{2-17}$ many have included few cases of proliferative retinopathy and have short periods of follow-up.

In this study diabetics without retinopathy achieved visual results comparable to those of controls. The patients with diabetic retinopathy,

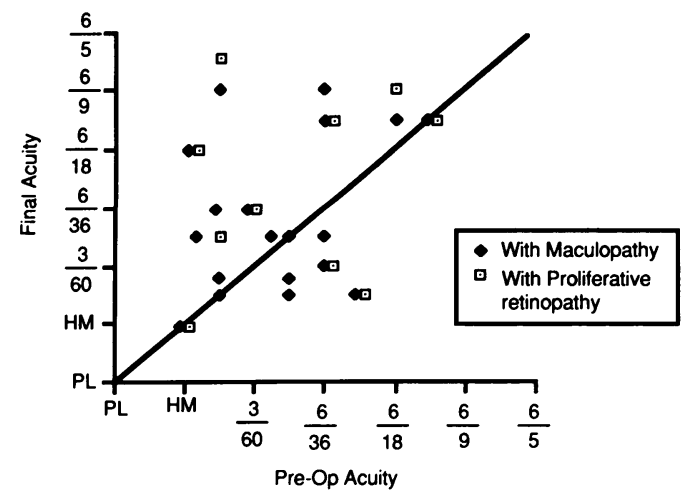

Figure 3 Scatter plot of preoperative and final visual acuity of diabetic eyes with proliferative retinopathy and maculopathy. Touching symbols are the same patient. particularly with maculopathy, fared less well. However, patients with maculopathy or severe retinopathy may have valuable visual improvement after surgery, and a clear optical axis may allow adequate laser photocoagulation to stabilise vision. Six of 10 eyes with proliferative retinopathy and seven of 19 eyes with preexisting maculopathy maintained $\geqslant 2$ lines improvement in Snellen acuity at a mean of 2.76 years follow-up (Figs 1-3). At final follow-up a total of 15 eyes had proliferative retinopathy and nine have maintained an improvement of $\geqslant 2$ lines Snellen acuity. Patients with proliferative retinopathy may achieve a worthwhile visual improvement so long as adequate preoperative (where possible) or early postoperative laser treatment is performed. We encountered no difficulty in performing laser photocoagulation through the IOL, and we consider that this group of patients should not be excluded from the optical advantages of an IOL.

In diabetics with pre-existing retinopathy cataract surgery has been reported to cause a severe form of exudative maculopathy in the early postoperative period. ${ }^{18}$ This occurred in nine eyes in our study. Seven of these eyes had pre-existing maculopathy and five had had previous laser treatment. Although the progression of maculopathy occurred soon after surgery, it is difficult to know whether the surgery was incidental. Several contributory mechanisms for example, intraocular inflammatory mediators such as prostaglandins ${ }^{19}$ - may be involved, but the aetiology remains obscure. But it is important that early postoperative assessment and treatment where necessary are performed. ${ }^{20}$

Patients with proliferative retinopathy who undergo lens extraction are at risk of developing rubeosis iridis, neovascular glaucoma, and vitreous haemorrhage. ${ }^{21}{ }^{22}$ Poliner et al suggested that an intact capsule helps to prevent the development of rubeosis..$^{22}$ In our study four eyes each with pre-existing proliferative retinopathy developed rubeosis at 12 to 18 months after surgery. Two of these occurred at four and five months respectively following YAG laser capsulotomy. It is clear that eyes with and without an intact capsule may develop rubeosis iridis, and early panretinal photocoagulation is needed to prevent development of rubeotic glaucoma. ${ }^{23}$

Previous reports ${ }^{4-7}$ have considered that an IOL and capsular thickening may prevent adequate postoperative laser treatment. In our study 23 diabetic eyes had distinct capsular thickening and 17 eyes received postoperative laser treatment (10 with PRP). Early, large capsulotomies can overcome the problems created by capsular thickening, and we encountered no difficulties in performing this laser treatment.

In conclusion, we consider that diabetics should no longer be excluded from the optical advantages of an IOL and that they have satisfactory visual results from this form of aphakic correction. However, these patients should be followed up closely postoperatively and any progressive retinopathy treated promptly.

1 Klein BEK, Klein R, Moss SE. Prevalence of cataracts in population-based study of persons with diabetes mellitus. Ophthalmology 1985; 92: 1191-6. 
2 Straatsma BR, Pettit TH, Wheeler N, Miyamasu W. Diabetes mellitus and intraocular lens implantation. Ophthalmology 1983; 90: 336-43.

3 Beckett R, Rosen ES. Results of the 1988 Survey on Cataract Surgery and Intraocular Lens Implantation in the United Kingdom. Eur F Implant Refract Surg 1989; 1: 231-5.

4 Thompson SM, Kritzinger EE, Roper-Hall MJ. Should diabetes be a contraindication for an intraocular lens? Trans Ophthalmol Soc UK 1983; 103: 115-7.

5 Patz A. Photocoagulation of retinal, vascular, and macular diseases through intraocular lenses. Ophthalmology 1981; 88: 398-406.

6 Jaffe NS. The way things were and are: changing indications for intraocular lens implantation. Ophthalmology 1983; 90: for intract

7 Tasman $W$. Are there any retinal contraindications to cataract extraction and posterior chamber lens implants? Arch Ophthalmol 1986; 104: 1767-8.

8 Clayman $\mathrm{HH}$, Jaffe NS, Light DS. Lens implantation and diabetes mellitus. Am $\mathcal{f}$ Ophthalmol 1979; 88: 990-2.

9 Sebestyen JG, Wafai MZ. Experience with intraocular lens implants in patients with diabetes. Am F Ophthalmol 1983; 96: $94-6$

10 Kennedy JE, Lim ASM, Ang BC. Posterior chamber intraocular lenses in diabetics. Aust $\mathcal{F}$ Ophthalmol 1984; 12: 253-6.

11 Alpar JJ. Cataract extraction and diabetic retinopathy. $\mathcal{F} \mathrm{Am}$ Intraocul Implant Soc 1984; 10: 433-7.

12 Ngui MSH, Lim ASM, Chong AB Posterior chamber intraocular lenses in diabetics. Int Ophthalmol 1985; 8: 257-9.

13 Sebestyen JG. Intraocular lenses and diabetes mellitus. Am $\mathcal{F}$ Ophthalmol 1986; 101: 425-8.
14 Alpar JJ. Diabetes: Cataract extraction and intraocular lenses. f Cataract Refract Surg 1987; 13: 43-6.

15 Fung WE. Phacoemulsification and implantation of posterior chamber intraocular lenses in eyes with quiescent proliferative diabetic retinopathy. Graefes Arch Clin Exp Ophthalmol 1987; 225: 251-3.

16 Hutton WL, Pesicka GA, Fuller DG. Cataract extraction in the diabetic eye after vitrectomy. Am $\mathcal{F}$ Ophthalmol 1987; 104: 1-4.

17 Cheng H, Franklin SL. Treatment of cataract in diabetics with and without retinopathy. Eye $1988 ; 2: 607-14$.

18 Jaffe GJ, Burton TC. Progression of nonproliferative diabetic retinopathy following cataract extraction. Arch Ophthalmol retinopathy following

19 Milch FA, Yannuzzi LA. Medical and surgical treatment of aphakic cystoid macular oedema. Int Ophthalmol Clin 1987; 27: 205-17.

20 Early Treatment Of Diabetic Retinopathy Study Research Group. Treatment techniques and clinical guidelines for photocoagulation of diabetic macular oedema. Early Treatment Of Diabetic Retinopathy Study Report No. 2. Ophthalmology 1987; 94: 761-74.

21 Aiello LM, Wand M, Liang G. Neovascular glaucoma and vitreous hemorrhage following cataract surgery in patients with diabetes mellitus. Ophthalmology 1983; 90: 814-9.

22 Poliner LS, Christianson DJ, Escoffery RF, Kolker AE, Gordon ME. Neovascular glaucoma after intracapsular and extracapsular cataract extraction in diabetic patients. Am $\mathcal{F}$ Ophthalmol 1985; 100: 637-43.

23 Murphy RP, Egbert PR. Regression of iris neovascularisation following panretinal photocoagulation. Arch Ophthalmol 1979; 97: 700-2. 